\title{
I en professur av glänsande stål. Vetenskapen historia - vad, varför och för vem?
}

\section{Av Frederic Bill}

\section{$1 \quad$ Inledning}

Den tyske 1800-talstänkaren Friedrich Nietzsche talar om tre olika typer av historiesyn, monumentalistisk, kritisk och antikvarisk.[1] Dennes resonemang kring synen på historia är tänkt att bilda utgångspunkten för denna text.

Var finns då den vetenskapliga synen på historia i Nietzsches resonemang? Han talar visserligen om en kritisk historia, men man skall komma ihåg att den vetenskapliga historieskrivningen som vi känner den idag inte existerade under Nietzsches livstid.

Men den kritiska historien i Nietzsches mening är inte i första hand revisionistisk, bildstormande, den är snarare ett komplement till monumentbyggandet. Liksom varje god historia kräver både hjältar och skurkar kan den kritiska historien förstärka den monumentala genom att peka på de negativa element som står hjälten emot. En enbart förhärligande historia blir platt och nyanslös. De dramaturgiska kraven gör därför att man också lyfter fram de mörka dragen: varje regim har sin Göran Persson.

Termen kritisk får här inte uppfattas som syftande på den källkritiska tekniken, utan det är fråga om en realhistorisk, existentiell eller politisk kritik.[2]

Den vetenskapliga, källkritiska historien har således ingen (given) plats i hans uppställning över de olika typerna av historia. Just detta, den vetenskapliga historiens frånvaro i mönstret kommer att behandlas ytterligare längre fram i texten.

Det finns dock ytterligare ett ledande tema för texten, nämligen makten och språket. Den franske vetenskapsteoretikern/filosofen Michel Foucault och hans diskursbegrepp kommer att härvid ligga som en, kanske delvis osynlig, botten i främst textens senare del. Denne menar att den som definierar vad som är "normalt" också skaffar sig makt över det offentliga samtalet och att "makten" i mer abstrakt mening har en mer eller mindre inneboende strävan att styra och/eller kontrollera samhällets olika diskurser.[3] Det bör dock tilläggas att resonemanget i denna text i huvudsak kommer att hållas på en annan abstraktionsnivå än vad som vanligen är fallet i Foucaults arbeten och att hans teorier bara till viss del kommer att användas. Det är således huvudsakligen relationen mellan makt och normering av språkbruket som här aktualiseras och det är knappast helt i enlighet med det bruk Foucault själv gjorde av diskursbegreppet.

\section{Historiens relevans}

Det relevanta i historien är absolut inte allom givet. Relevans är ett begrepp som inte kan stå för sig själv utan är till sin natur sådant att det måste sättas i relation till ett syfte eller mål.

Därmed kan man inte automatiskt sortera historien och historieskrivningen i relevanta och irrelevanta delar. Relevansen är således beroende av syftet, av vilken historia man åstundar. Den antikvariska historien t ex är till sin natur emotionell, den har sitt värde i fascinationen och välbefinnandet inför en historisk kvarleva. Den visserligen svårartikulerade men i 
grund positiva känsla man får inför något gammalt är till själva sin natur både personlig och okritisk. Detta skulle dock även kunna sägas om den monumentalistiska historien, monumentet spelar på empatins strängar med syfte att förmedla en känsla till "betraktaren". Det finns dock en skillnad däri att monumentet måste lyftas fram, måste skapas för att kunna fylla sin funktion av känsloförmedlare. Detta betyder naturligtvis inte att monumentskaparen måste vara en tydligt definierad individ eller grupp av individer. Monument kan sannolikt även skapas kollektivt, utan ett medvetet bakomliggande syfte. Den monumentalistiska historien befinner sig dock i alla händelser på en högre abstraktionsnivå då känslorna inför monumentet per definition riktar sig utåt, de är samhörighetsskapande och avskiljande. Detta till skillnad från de antikvariska känslorna, vilka inte på samma sätt behöver en omgivning för sin relevans.

Vad gäller Nietzsches resonemang om den kritiska historien, kan man nog se denna mer som en fördjupning av den monumentalistiska historien än som en i detta sammanhang helt fristående typ av historia. Med detta sagt måste dock erinras om det faktum att monumenten i sig inte behöver individualiseras, t ex det "svenska" folkhemmet är en monumentalistisk företeelse som i egentlig mening är opersonlig även om man naturligtvis kan lyfta fram individer som monument över monumenten för att begripliggöra företeelsen. Per-Albin Hansson som monument förutsätter (åtminstone till viss del) monumentet folkhemmet. Raseras det grundläggande monumentet raseras samtidigt det individuella monumentet. Det skulle nog i och för sig vara klokare att i detta sammanhang tala om betydelseförändring än rasering. Förvandlas monumentet folkhemmet i diskursen till en belastning torde ju inte detta medföra monumentet Per-Albin Hanssons omedelbara demonumentaliserande utan bara hans framlyftande som ett negativt monument. Vi har t ex exemplet Stalin som ju förvandlats från ett positivt monument över kommunismens framsteg till ett negativt dito över kommunismens ondska.

Relevansen är således beroende av syftet, vilket också kan sägas om monumenten. De kan användas även av andra och blir därigenom extra kraftfulla just genom sin bindning till skaparen. Detta äger naturligtvis extra sanning då samhällets metanormer skiftar och gamla vedertagna sanningar blir gamla betungande uttalanden.

Det går således inte att förneka historiens politiska dimension, åtminstone inte vad gäller kritisk eller monumentalistisk historia. Detta illustreras mycket tydligt av citatet från Scott nedan:

For centuries, those advocating the elevation of women's status have culled the past for examples of exemplary figures: It is evidence of the way feminists in the past have turned to history to legitimate their demands, ..if womens subordination - past and present - was secured at least in part by their invisibility, then emancipation might be advanced by making them visible in narratives of social struggle and political achievement.[4]

Det finns således, för att föregripa nästa kapitel, åtminstone två olika slags vetenskapliga historiska relevanser. Den inomvetenskapliga och den utomvetenskapliga.[5] Generellt skulle man t om kunna tala om tre huvudtyper av historisk relevans, emotionell, politisk och vetenskaplig. Detta skall dock inte förstås som att all historia kan delas in och sägas vara relevant i "sitt" fack, historiska aspekter kan naturligtvis vara relevanta inom två eller alla tre av dessa typer. Det kan naturligtvis förefalla anmärkningsvärt att tala om en inomvetenskaplig relevans hos emotionell historia, men de känslor historien väcker påverkar naturligtvis även den aldrig så objektive historikern i högre eller mindre grad och en förståelse för denna påverkan kan naturligtvis öka förståelsen för historiens talrika berättande källor. Själva känslorna i sig är dock utomvetenskapliga medan kunskapen om dem kan vara såväl utom- som inomvetenskaplig.

\subsection{Vetenskaplig historia}

Var passar då den vetenskapliga historien in i Nietzsches struktur? Frågan kan verka 
naturlig, men faktum är att den är felformulerad. Frågan borde egentligen vara: Passar den vetenskapliga historien in i Nietzsches mönster? Utelämnandet av den kan ses som en handling som verkar vara en tanke. Nietzsche diskuterar historia utifrån i huvudsak två perspektiv, han ser dels en emotionell, dels en funktionalistisk eller om man så vill politisk nivå i historien. Vetenskap i modern mening, frågan "Hur var det egentligen?" har ingenting med resonemanget att göra. Positivistisk vetenskapsteori, i alla dess nyanser och skepnader, är till sin art icke-emotionell även om inte heller detta är en sanning helt utan modifikation. Således kan vetenskapen historia tyckas falla utanför ramarna för vad historia enligt Nietzsche är, men i realiteten är det naturligtvis inte så. Det är trots allt så att vetenskapen har ombesörjt framplockandet av monumenten, av Nietzsches hjältar och skurkar. Dessa, ofta storvulna, berättare betraktas dock numera ofta som lätt löjliga. Vem inom vetenskapssamhället drar inte på munnen åt t ex Rudbecks "Atlantican" eller Lindqvists "Historien om Sverige"? Paradigmet har skiftat och språket, eller om man så vill diskursen, har ändrats. Numera är det "den oberoende forskningen" som sätter standarden för vetenskapssamhället och den vetenskapliga diskursen.

Slutsatsen här måste bli att den vetenskapliga historien har möjligheten att själv normera sin existens, den kan vara antikvarisk, monumentalistisk, politisk, kritisk, vetenskaplig eller kanske t om allt på en gång. Detta skall dock inte tolkas eller förstås som att valet saknar betydelse och konsekvenser.

\subsection{Teorianvändningen}

Detta kapitel syftar till att fragmentariskt belysa sambandet mellan historisk teorianvändning och normerandet av historievetenskapen som historia. Det torde vara lämpligt att först konstatera att det inom historievetenskapen finns dels samhällsteorier som i grund och botten är politiska (men därigenom inte automatiskt ovetenskapliga) och sådana som i grund och botten är vetenskapsteoretiska (men därigenom inte automatiskt opolitiska).

Ett tydligt exempel på den förra typen är naturligtvis den ur marxismen stammande historiematerialismen,[6] men även i någon mån genusperspektivet som, vilket citatet av Scott ovan visar, har åtminstone delar av sina rötter i feminismen. Risken med denna typ av teorier är självklar, teorin om t ex klasskampen och makten över produktionsmedlen som det drivande bakom historiens förlopp kan lätt användas axiomatiskt. På samma sätt förhåller det sig med genusperspektivet om kvinnans underordning. Dessa utgångspunkter måste styrkas för att hålla som vetenskap, om man som t ex Maria Sjöberg i följande citat utgår från vissa teoretiska antaganden utan att "bevisa" dem torde man röra sig inom en politisk snarare än vetenskaplig historia.

De flesta som studerar olika maktförhållanden, t ex kolonialism eller klassförhållanden, utgår ju på ett eller annat sätt från den kunskap om dessa maktrelationer som redan är känd. Ingen har något att invända mot det. Varför kan inte detta gälla också i fråga om maktrelationer mellan könen. Vi har förvisso begränsade kunskaper om det äldre samhället, men så mycket vet vi att kvinnan saknade de juridiska rättigheter mannen hade. Andersson vill ändå veta om kvinnan var underordnad eller ej. Det förefaller onekligen ganska onödigt."[7]

Man kan naturligtvis tänka sig en hel rad mer eller mindre giltiga invändningar mot Sjöbergs antagande, men dessa faller tyvärr utanför ramen för denna text. Det intressanta här är just hennes sätt att axiomatiskt utgå från en osäker utgångspunkt.

Vad gäller mer poitivistiskt inriktade teorier är ju dessa till själva sin natur vetenskapliga, men de behöver genom detta inte vara opolitiska, eller för att citera Ingvar Johansson "Är sanningen alltid politiskt neutral?"[8]. Det finns alltid ett spelrum för forskaren när det gäller att lyfta fram eller "finna" olika sanningar och den allra mest vetenskapliga teori är fortfarande beroende av användaren för att prestera vetenskapliga eller om man så vill 
objektiva slutsatser. Till syvende och sist är trots allt historisk forskning lite som att leka jeopardy, källmaterialet ger svaren men forskaren måste själv ställa de rätta frågorna.

Så framträder för vår blick inget annat än en sanning som tycks vara rikedom, fruktbarhet och kraft - mjuk och försåtligt universiell. Däremot förblir vi okunniga om viljan till sanning, okunniga om det oerhörda maskineri, avsett att utestänga som den är. Alla som gång efter annan under historiens lopp försökt dra upp konturerna av denna vilja, alla som försökt ifrågasätta den genom att ställa den mot sanningen just där sanningen försöker berättiga förbudet och definiera vansinnet - alla dessa alltifrån Nietzsche till Artaud och Bataille kan idag tjäna som (förvisso upphöjda) förtecken för vårt dagliga arbete.[9]

\section{Varför vetenskap?}

Vad säger då detta oss om förmedlandet till den bredare allmänheten av historia som vetenskap. Både ordet vetenskap och ordet historia är ju som de tidigare kapitlen visat ganska oklara begrepp. Vad är historia och vad är vetenskap? Dessa båda begrepps innebörd har i det förflutna genomgått betydelseförändringar och även om den nu dominerande ståndpunkten om historievetenskapen som en källkritisk, objektiv och argumentativ vetenskap kan tyckas självklar är det inte nödvändigtvis så. En ståndpunkt blir inte korrekt genom att den förfäktas av flertalet. Det kan här vara fruktbart att peka på Kuhn och hans teorier om paradigm och normalvetenskap. Enligt Kuhn befinner sig ett vetenskapssamhälle i dels stadier av normalvetenskap där man arbetar inom ett vedertaget paradigm och dels i stadier av revolutionär vetenskap då paradigmet ifrågasätts.[10]

En i vissa kretsar ofta förbisedd aspekt av det i tidigare stycken förda resonemanget blir naturligtvis att det finns flera sorters historia, vilka kan existera parallellt. "Vetenskapliga" historiker vill ofta låta påskina att deras historia, den vetenskapliga, är den "rätta" historien och att andra sorters historia är "fel" historia. Motiveringen bakom detta resonemang är då att just den vetenskapliga historien beskriver "sann historia" medan andra sorters historia beskriver "osann historia". Detta sätt att argumentera är dock inte giltigt utifrån Nietzsches perspektiv på och klassifikation av historia. Sanningen, hur det egentligen var, är inte nödvändigtvis det enda perspektivet på historia. Enligt ett sätt att tolka Nietzsche handlar historia åtminstone till en del om känslotillstånd och kan således inte behandlas enbart utifrån ett sant/falskt perspektiv. Visst ligger det nära till hands att se ner på den historia som Lindqvist skapar eller den Rudbeck skapade med motiveringen att den ju inte är sann, men detta är knappast ett fruktbart angreppssätt. Antagandet om den "sanna historien" som den "rätta historien" är påfallande likt ett Kuhnskt paradigm,[11] varför det inte gäller a priori utan kan diskuteras. Denna diskussion lyser dock till stor del med sin frånvaro och ersätts med axiomatiska påståenden om att vissa historieberättare har fel i sak. Göticism, revisionistisk forskning kring andra världskriget, hembygdsforskning och programmatisk feminism av Sjöbergs typ är, för att ta några spridda exempel, historia som monument, politik och/eller antikvarism. Dessa historietyper är vanligen inte lika objektivt sanna som den nu förhärskande vetenskapliga historien men de är därigenom inte nödvändigtvis sämre historia. Kritik av t ex Rudbeck för bristande objektivitet blir lätt anakronistiskt då objektivitet så vitt man kan förstå knappast var vad som först och främst eftersträvades i t ex hans Atlantican. För att återknyta till kapitel 2 är således historiens relevans beroende av syftet, men inte nödvändigtvis sanningshalten. Konklusionen blir då att falska påståenden om det förflutna kan vara historiskt relevanta, något som naturligtvis inte gör dem historiskt sanna.

Man kan, för att återknyta till Foucault, se kampen om det historiskt relevanta som ett uttryck för en kamp om språket, en strid om rätten till diskursen.

\subsection{Kommunikation av vetenskap}

Vilka följder får då det ovan sagda för historieförmedlingen, för hur historieämnet som 
vetenskap skall nå ut till allmänheten. Denna fråga skall i detta kapitel behandlas ur några olika aspekter.

Varför skall just objektiv historia förmedlas?

Mot bakgrund av det ovan sagda om historiens relevans måste man fråga sig varför just vetenskapligt objektiv historia skall förmedlas och ges utrymme i samhällsdebatten. Mot bakgrund av Ingvar Johanssons fråga om sanningen som politiskt neutral bör man konstatera att det mycket väl kan finnas en ovilja mot denna typ av historieskrivning från stora och eventuellt även maktbärande grupper i samhället. Objektivt vetenskaplig historia skiljer sig nämligen på en mycket avgörande punkt från alla andra typer av historia, den är inte förhandlingsbar på samhällsnivå. Vetenskap skrivs av vetenskapsmän och dessa har just i kraft av sin kompetens och sin roll som vetenskapliga auktoriteter större tyngd i debatten kring "sitt ämne" än en aldrig så högaktad politiker eller samhällsdebattör. Den objektivt vetenskapliga historien har således en inneboende kraft att normera det offentliga samtalet, en kraft som saknas hos andra typer av historia. Främst politiskt syftande historia fordrar t ex externt stöd för att kunna dominera samhällsdebatten, något som exemplifieras men egentligen inte bevisas av olika totalitära staters medvetna strävan efter att påverka och dominera historieskrivningen. Man kan i detta sammanhang även lyfta fram Foucaults teorier om makten och diskursen, hans utestängningens mekanismer,[12] som ytterligare ett belägg för sanningens inneboende kraft. Resonemanget bygger naturligtvis på antagandet av det faktum att då sanningen konfronteras med osanningen torde allt annat lika sanningen alltid dominera. Förhållandet att sanningen vanligen kan styrkas även empiriskt, åtminstone inom historievetenskapen, ger den en inneboende kraft som i hög grad saknas hos osanningen. Mot bakgrund av detta skulle man, med risk att bli dogmatiserande, kunna klassificera den objektiva vetenskapliga historien som den högsta formen av historia.

Med detta sagt kan resonemanget kompliceras ytterligare genom att istället kategorisera den objektiva vetenskapliga historien som den lägsta formen av historia, som ett perspektivlöst sökande efter "trista" sanningar. En närmast antikvarisk vurm för fakta om vad Clarendon kallade "dirty people without names".[13]

Det som skall lyftas fram här är dock den objektiva historiens värde oavsett perspektiv. I det första fallet står den som en oomkullrunkelig sanning, en given norm vilken man oavsett syftet med sin historieskrivning inte kan negligera och i det andra fallet bildar den en empirisk grund på vilken man kan bygga historia som fyller de syften man ställer upp för den.

Vad är det som skall förmedlas?

Accepterar man antagandet att den objektivt vetenskapliga historien har ett inneboende värde och av denna anledning bör förmedlas till breda lager av allmänheten måste man också fråga sig vad det är som skall förmedlas. Vetenskapssamhället producerar enorma mängder av texter och avhandlingar, varför någon form av urvalsmekanism måste användas (om inte annat den rena slumpen). Det torde dock finnas ett ganska självklart svar på frågan om vad som bör förmedlas till allmänheten. Det finns naturligtvis såväl inomvetenskaplig som utomvetenskaplig relevans t o m i objektivt vetenskaplig historieskrivning.

Historia kan vara vetenskapligt relevant ur tre olika aspekter, en kumulativ, en teoretisk och en existentialistisk aspekt.[14] Vad gäller de två första och allra främst den andra aspekten är dessa naturligtvis främst inomvetenskapligt relevanta, de tjänar att fördjupa och bredda disciplinen. Den tredje aspekten däremot kan naturligtvis även den vara inomvetenskapligt relevant, men den är också utomvetenskapligt relevant.

Det är naturligtvis så att de i huvudsak inomvetenskapligt relevanta delarna av den objektivt vetenskapliga historieskrivningen saknar egentligt "värde" för den bredare allmänheten. Man kan dels dra i frågomål huruvida de är begripliga och man kan vidare fråga sig om de i sin egenskap av verktyg verkligen är intressanta utanför vetenskapsamhällets smala krets. Då detta i och för sig inte är en helt oproblematisk 
inställning inom humanioraämnena skall här understrykas att frågan om den inomvetenskapliga historieskrivningens värde för allmänheten är starkt förknippad just med det humanistiska arvet. I en text om matematiska bevisföringsmetoder hade sannolikt ett påstående om det bristande värdet för allmänheten varit mindre kontroversiellt - är historikern berättare eller vetenskapsman?.

Vad gäller huvudsakligen kumulativt relevant historia kan däremot denna, åtminstone i vissa fall, appelera till läsare och lyssnare utanför vetenskapens inre krets. Den existensialistiskt relevanta historien slutligen, har goda möjligheter att kunna anammas av allmänheten förutsatt att den presenteras på ett tillgängligt sätt. Det torde här vara av intresse att beakta hur historia av detta slag förmedlas i dagsläget och möjligen även att beakta andra sätt för historieskrivningen att nå ut med sitt budskap.

Vill vetenskapshistorikerna nå ut?

En fråga som nära anknyter till resonemanget ovan är om vetenskapsmännen faktiskt vill vara begripliga för den breda allmänheten. Vad ger status inom vetenskapssamhället? Är det förmågan att nå ut med sin kunskap till breda folklager eller är det att vara teoretisk, svår och otillgänglig? Det är ju onekligen så att dagens vetenskapsmän, åtminstone inom vissa vetenskaper, i högre grad än tidigare sitter i sina elfenbenstorn och värjer sig mot folkligheten eller åtminstone ser ner på den. Under 30-talet skrev t ex nationalekonomer som handelshögskolans professor Cassel och hans efterträdare Myrdal i "Tiden" och i kooperativa förbundets häften på samma gång som man var skribenter i "Ekonomisk tidskrift" och deltog i Nationalekonomiska föreningen. Var finner vi dagens professorer i t ex nationalekonomi och historia? Sitter de mitt i samhälldebatten eller i sina slutna seminarierum och skriver för en begränsad skara? Var finns den eftertraktade förmågan att tala till bönder på bönders vis och till lärde på latin? Med detta sagt skall man dock hålla i minnet att felet, om man kan tala om ett sådant, inte nödvändigtvis behöver ligga hos vetenskapsmännen. Det kan säkert i hög grad förhålla sig på det viset att utrymmet för populärvetenskapligt författande och samhällsengagemang inom de akademiska tjänsterna har minskat på samma gång som det dessutom i viss mån saknas forum för denna typ av författande. Oförmågan eller oviljan att tala till bönder på bönders vis kan således vara strukturellt snarare än individuellt betingad. Dessa förhållanden gör dock inte frågan mindre berättigad, de pekar däremot på en tänkbar riktning för ett eventuellt förändringsarbete.

\section{Historikern och framtiden?}

Foucault talar om en ny historisk metodik, om en förhöjd upplösning av analysen ända ner till torgprislistor och hamnarkiv.[15] Nietzsche å sin sida talar om en fjärde typ av historia, en existentiell historia som beskriver kärleken, grymheten och allt annat som ger livet färg.[16] Just detta, det sena 1900-talets framvaskande av enorma faktamängder ger ny vitalitet åt historieämnet, ger verkligen möjlighet till en "totalhistoria". Det är dock inte en oproblematisk utveckling för samtidigt ställer detta helt nya krav på effektiva urvalsmetoder för kunskapsförmedlingen, såväl den inom- som utomvetenskapliga.

Historieämnets berättigande, alltså den objektivt vetenskapliga historieskrivningens berättigande står naturligtvis inte att finna i den inomvetenskapliga relevansen. En vetenskap kan inte berättiga sin existens med sina egna behov utan dess berättigande måste vara utomvetenskapligt, disciplinen måste berättiga sin existens genom sin nytta för andra. För vem är då den objektiva vetenskapen till nytta? Den är egentligen inte nödvändig för politiskt relevant historia, även om den i vissa fall kan styrka och underlätta denna, och den är egentligen inte nödvändig ur ett existentialistiskt perspektiv. De individer och grupper som söker bekräftelse och perspektiv i historien skulle sannolikt klara sig lika bra med Lindqvists eller Rudbecks typ av historieskrivning. För dem är inte den intersubjektiva prövbarheten eller den källkritiska metoden särskilt avgörande, det är alltså inte sanningen i objektiv mening som är det viktiga för dessa historiekonsumenter. Kvar finns då egentligen bara en enda väg till berättigande, den långa, svåra och krokiga väg 
som inte sällan måste vandras i motvind och leder till sanningen. Det ovan angivna citatet av Foucault pekar dock på riskerna med sanningen som begrepp, inte minst genom svårigheterna att definiera denna.

Tyvärr ger vår moderna historia tydliga exempel på vad som kan hända när den politiskt relevanta historien eller om man så vill historieförfalskandet får skaffa sig makt även över sanningen, vestigia terrent. Detta skall dock inte ses som ett generellt fördömande av all historieskrivning syftande till att ifrågasätta etablerade myter och sanningar. Den objektivt syftande historikerns själva väsen, hans arbetsredskap, är just misstron, kritiken och ifrågasättandet. Det är däremot viktigt att särskilja mellan ett ifrågasättande som syftar till att finna sanningen och ett ifrågasättande som syftar till att lyfta fram eller bevisa Sanningen. På samma gång som man måste hysa en ständig kritik, mot förhärskande dogmer och lokala eller aldrig så hyllade potentater, är draget av lyssnande och reflektion det som kanske mer än något annat utmärker en objektivt kritisk historieskrivare. Vetenskap utmärks kanske mer än någonting annat av just förmågan att bygga vidare på den grund som andra har lagt, under ständiga reflektioner över värdet av och syftet med det som bildar den grund på vilken man bygger sitt bidrag till vetenskapen.

Kanske har då den objektiva vetenskapens historia åtminstone en del av sitt berättigande just genom sin roll som vetenskap. När näste Adolf Hitler eller Josef Stalin ger sig på sanningen för att vrida och vända den efter sina egna syften hoppas vi väl alla att det står en Ankarloo, en Olsson eller en Österberg i vägen. I professurer av glänsande stål, med svärdet i ena handen och uriebrevet i den andra. Beredda till bådadera.

(C) Frederic Bill, studerande vid Växjö universitet

[1] Ankarloo Bengt 1992 Om historiens nytta i Ut med historien - Historieundervisningens uppgifter idag (Red Österberg och Bodgren) s 18

[2] Ankarloo Bengt 1992 Om historiens nytta i Ut med historien - Historieundervisningens uppgifter idag (Red Österberg och Bodgren) s 25

[3] Foucault Michel, Diskursens ordning Brutus Östlings bokförlag 1993 t ex s 7-9

[4] Scott Joan Wallach Introduction i Feminism and History (red Scott) Oxford 1996

[5] Dahlgren Stellan, Florén Anders Fråga det förflutna Studentlitteratur, Lund 1996 s 73, 76-77

[6] Johansson Ingvar, Liedman Sven-Eric Positivism och Marxism Daidalos 1997 s 166-173

[7] Sjöberg, Maria. Kvinnans underordning - en undantagshistoria? Historisk tidskrift 1997:3 s 459

[8] Johansson Ingvar, Liedman Sven-Eric Positivism och Marxism Daidalos 1997 s 32

[9] Foucault Michel, Diskursens ordning Brutus Östlings bokförlag 1993 s 15

[10] Johansson Ingvar, Liedman Sven-Eric Positivism och Marxism Daidalos 1997 s 50-54

[11] Johansson Ingvar, Liedman Sven-Eric Positivism och Marxism Daidalos 1997 s 51-52

[12] Foucault Michel, Diskursens ordning Brutus Östlings bokförlag 1993 s 14

[13] Ankarloo Bengt 1992 Om historiens nytta i Ut med historien -

Historieundervisningens uppgifter idag (Red Österberg och Bodgren) s 22

[14] Dahlgren Stellan, Florén Anders Fråga det förflutna Studentlitteratur, Lund 1996 s 77

[15] Foucault Michel, Diskursens ordning Brutus Östlings bokförlag 1993 s 38-39

[16] Dahlgren Stellan, Florén Anders Fråga det förflutna Studentlitteratur, Lund $1996 \mathrm{~s}$

157 